\title{
The Impact of Non-farm Activities on Poverty Reduction among Rural Farm Households in Ambo District of West Shoa Zone, Oromia Region, Ethiopia
}

\author{
Zewdu Adefris $^{1 *} \quad$ Birhanu Woldeyohannes ${ }^{2}$ \\ 1.Department of Development Economics, Ethiopian Civil Service University, PO box 5648, Addis Ababa, \\ Ethiopia \\ 2.Addis Ababa Transport Bureau Technical and Financial Capacity Building Director, Ethiopia
}

\begin{abstract}
This study investigated the impact of cash-oriented non-farm activities on poverty reduction among rural farm households in Ambo district of West Shoa zone of Oromia region, Ethiopia. It was conducted in the five selected kebeles; namely Golja, Ya'i Chebo, Uko Korke, Ilamu Goromti and Birbirsa Kulit. Cross-sectional survey was employed to collect data from 300 respondents, in which 150 were participants and 150 were non-participants in remunerative non-farm activities. The cost of basic needs approach was used to estimate absolute poverty line, and the Foster, Greer and Thorbeck index to determine the incidence, depth and severity of poverty among participant and non-participant households. The study employed logit model to identify determinants of non-farm activities participation and propensity score matching method to analyze the impact of non-farm activities on poverty. The study finds that $26.33 \%$ of households in the study area are poor. The incidence, depth and severity of poverty were found to be higher among non-participant households than among participant households. The result of logit regression indicated that gender, marital status of household head, dependency ratio, skill, access to credit and distance to the nearest market are identified as determinants of participation in non-farm activities. The propensity score matching results indicated that participation in remunerative non-farm activities has a significant effect on the households' consumption expenditure level. The average treatment effect of treated indicated that, the average monthly per capita consumption expenditure of participant is birr 72.31 more than non-participants households. These results indicate that the participation in remunerative non-farm activities improved the livelihood of households in the study district. Thus, while this study is not advocating for non-farm economic activities as a substitute to farming, non-farm work could be a reliable complement to farming activities. The promotion of nonfarm activities in addition to farm activities seems indispensable to alleviate rural poverty.
\end{abstract}

Keywords: Poverty, Rural farm households, Impact, Non-farm activities, Propensity score matching

DOI: $10.7176 / \mathrm{JPID} / 58-02$

Publication date: January $31^{\text {st }} 2021$

\section{Introduction}

In developing countries, non-farm activities play a more and more important role in sustainable development and poverty reduction in rural areas. Non-farm activities can influence the rural economy through various channels. First, non-farm employment ${ }^{1}$ reduces the pressure on the demand for land in poor areas. Consequently, non-farm activities can contribute to breaking the vicious cycle of "poverty - extensive cultivation - ecological deterioration - poverty". Second, the income obtained from non-farm activities can significantly increase total household income and hence enhance the investment capacity in farm activities. It can also mitigate income fluctuations and enable the adoption of some more profitable but "risky" agricultural technologies, which favour the transformation of traditional agriculture to modern agriculture. Third, non-farm income is often a source of savings, which plays an important role in poverty reduction.

In Ethiopia, agriculture is a dominant sector where about $85 \%$ of the population earns their livelihood from agriculture. Given the increasing population growth in rural Ethiopia and the relatively limited quantity of cultivable land, the agricultural income per capita has been low. In such a situation, non-farm sectors can play an important role in absorbing the surplus agricultural labour, in enhancing the income of farmers, and in reducing rural poverty. Thus efforts to promote rural development, which includes progress both in farm and non-farm activities, will help to bring better days in Ethiopia. Non-farm activities provide not only alternative sources of income and employment for the rural poor but also stimulate agricultural production.

Non-farm sector has a potential contribution in the livelihood of rural household as it provides alternative source of rural income generating activities which improves distribution of income, contributes to the growth of rural economy and strengthen poverty alleviation efforts [9]. [10] evaluated how participating in both wage- and self-employment non-farm work impacts on farm household income. The results from the study showed that nonfarm employment has a positive and robust effect on farm household income and way out of poverty.

\footnotetext{
${ }^{1}$ Non-farm employment refers to employment not related to farming activities.
} 
There is a rapid population growth in Ethiopia which resulted in small and fragmented land holding reducing labour productivity and leading to a widespread underdevelopment over the country. The rapid growth rate of youth population, especially, led to youth dependency burden which in turn increases the consumption of basic goods and services and decreases the capacity of domestic savings affecting investment and economic growth [18]. In addition to land scarcity, agricultural production seasonal and, therefore, rural labour cannot be employed throughout the year which needs to widely develop non-farm activities [19]. These non-farm activities diversify the economy and it could be a crucial strategy for the government to fight against poverty, as it absorbs labor thereby minimizing unemployment. But, the existing development conditions give less attention to non-farm activities and their linkages to agriculture. This is partly due to the fact that the role of the rural non-farm sector in the rural economy is underestimated [8].

In the area of study, little study has been conducted in the area to explore the potential impact of cash-oriented non-farm activities on poverty reduction among rural farm households. Thus, this study by investigating the determinants and impact of non-farm activities on poverty reduction among rural farm households in Ambo district of West Shoa Zone, Oromia Region would provide necessary analytical insights for targeting the rural non-farm activities in the study area.

The general objective of the study is to investigate the impact of non-farm economic activities on poverty reduction among rural farm households in Ambo district of West Shoa Zone, Oromia Region, Ethiopia.

The specific objectives are:

$>$ To measure the extents, depth and severity of rural poverty in the study area;

$>$ To identify the determinants of participation in non-farm activities among rural farm households in the study area;

$>$ To examine if participation in remunerative non-farm activities significantly reduces household poverty.

\section{Literature Review}

\subsection{Poverty line}

A poverty line indicates deprivation in an absolute sense, and it refers to the minimum level of income or expenditure deemed necessary to achieve the minimum requirements of life (wellbeing). It is a line below which one is simply considered as poor and above which one is not. The poverty line may be thought of as the minimum expenditure required by an individual to fulfill his or her basic food and non-food needs, and it obtained by specifying a consumption bundle considered adequate for basic consumption needs and then by estimating the cost of these basic needs [20].

However, the central question in the poverty analysis is how to set this arbitrary line in order to distinguish the households or individuals into two categories (i.e. Poor or non-poor). There are a number of approaches to set poverty line such as; direct calorie intake (DCI), food energy intake (FEI), and cost of basic need methods (CBN). The first two approaches are not commonly applicable due to the overlooking of food basket identification and lack of scaling of the quantities according to the corresponding nutritional requirements of age-sex profile of the individuals. Hence, in the study area, the CBN approach is used to estimate absolute poverty line. It is the most widely used method of setting a poverty line. In the CBN method, the food poverty line defined by selecting a 'basket' of food items typically consumed by the poor and quantity of the food basket scaling up or down until that the given bundle meets the predetermined level of minimum caloric requirement and valued at the relevant market prices. In this method, poverty is normally a lack of command over basic consumption needs and poverty line defined as the cost of basic needs [11]. After determining the food poverty line, adjustments are then made for non-food expenses.

\subsection{Impact of rural non-farm economy}

According to [18], non-farm activities include all secondary and tertiary sector employment of both permanent and casual nature. Since these activities are quite diverse, a number of different terms are used in the literature to refer to non-farm employment. Broadly speaking, non-farm activities in the rural areas can be divided into the following categories:

- Small-scale industrial activities such as food processing (flour milling, oil processing, soap making and food processing)

- Cottage industries (handicrafts, spinning of cotton or wool, cloth weaving and dying, pottery, leather tanning and distilling local brews)

- Artisan activities (blacksmiths, masonry, wood work/carpentry, house construction, repair services and fabrication of farm tools)

- Commercial activities (trade and transportation)

- Infrastructure development activities (special public works, feeder roads and irrigation works, and foodfor-work programs) and

- Formal employment including professional and administrative jobs. 
A poverty profile simply describes the pattern of poverty, but is not mainly concerned with explaining its causes. Poverty may be due to regional characteristics like ecological or geographical isolation, low resource base, shortage of rainfall, and other inhospitable climate, good governance, economic, political and market stability. It may be due to community level characteristics such as infrastructure, human resource development, access to employment, social mobility and land distribution; household and individual characteristics like the age structure of the family members, education, gender of the household head and the extents of participation in the labor force [20].

Several grounds are pointed out on the desirability of developing the non-farm sector as a vehicle to reduce rural poverty. Among them are: the growing rural communities cannot be sustained by the agricultural sector alone; rural economies are not purely agricultural and most of the rural communities derive their incomes from various sources rather than from agriculture per se; avoid rural-urban migration; reduce the rural-urban economic disparities; reduce rural unemployment since rural industries are usually labour-intensive and hence, expected to absorb more labour; intensifies linkages between industry and agriculture, and thus support agricultural growth; reduce income inequality in the rural areas since the lower income group is expected to participate more intensely in non-farm activities; and encourage the participation of women in the non-farm sectors and hence empowering them [16].

Several cross-sectional studies in Africa and Latin America show a positive correlation between non-farm participation and total income [13]. Some studies also found non-farm employment contributing to increase in agricultural investment [18]. These findings suggest that, expansion of non-farm economy may play a positive role in reducing poverty.

Non-farm expansion can play a significant role in reducing poverty if most of the poor have access to employment in the sector. But it is not always the case that the non-farm sectors are more inclusive of poor. In east Africa household members from low-agricultural potential are found to be more likely to be engaged in the nonfarm sector than those in high-agricultural potential [18].

While there is evidence of positive correlation between non-farm participation and total income across several countries, the relationship between the share of non-farm income and total income or wealth is not so uniform. In some cases the poor get a higher share of their income from non-farm activities [1] thereby expansion of the nonfarm sector contributes to greater equality while in others, as shown for most of African studies [12], the rich and wealthy get a higher share of their income from non-farm activities implying an inequality increasing non-farm economy.

\section{Research Methodology}

\subsection{Poverty measures}

\subsubsection{Setting poverty line}

In this study, the CBN approach was used to estimate absolute poverty line. In the CBN approach, first order ascendingly the households according to the consumption expenditure and the poorest $50 \%$ of the sample population identified as a reference group. The food consumption behaviour of the reference group also accessed to determine average quantities per adult equivalent of basic food items that make up the reference food basket. Second, the total calorie obtained from the consumption of average quantity per adult estimated based on the [21] food nutrition table. The average quantity per adult of each food item is scaled up and down by a constant value (ration of recommended calorie of per day per adult to the total calorie obtained by individual adult from consuming the average quantities) so as to provide the recommended calorie per adult per day. Third, multiply each food item by the median price and sum up to get a food poverty line. Consequently, the necessary allowance for the basic non-food item was made to get a non-food poverty line and finally the total poverty line obtained by the sum of food and non-food poverty line.

In line with [11], the mathematical formulation used to set food poverty line is stated as follows:

The total amount of calorie value obtained from the consumption of the specified basket of average quantity per adult by an individual is:

Where,

$$
\sum q_{i} \text { Kcal }_{i}=T^{*} \text { with } T \cong T^{*} . \text { But } T \neq T^{*}
$$

$\mathrm{T}^{*}=$ total calorie obtains by individual adult from consumption of the average quantities.

$q_{i}=$ average quantity per adult of food item ' $\mathrm{i}$ ' consumes by individual.

Kcali $=$ the caloric value of the respective of each food item ' $\mathrm{i}$ ' consumes by individual adult.

$T=$ the value of nationally recommended calorie requirement per day per adult (in this case,

2200 kcalorie).

First, the average quantity per adult of each food item scale up and down by a constant value $\left(\frac{T}{T^{*}}\right)$ is obtained in order to get the exact value of recommended Kcalorie (2200 kcalorie per adult per day). Then, multiply each food item by the median price and sum up to get a food poverty line. The subsequent step is to estimate the non-food 
component of the total poverty line. The non-food share of total expenditure estimates through regressing the food share $\left(\mathrm{S}_{\mathrm{i}}\right)$ of each household ' $\mathrm{i}$ ' on a constant and the log of the ratio of total consumption expenditure to the food poverty line $\left(Z^{f}\right)$ :

$$
S_{i}=\alpha+\beta \log \left(\frac{Y_{i}}{Z^{f}}\right)+\epsilon
$$

where, $S_{i}$ refers to the share of food item from the total household expenditure, $Y_{i}$ denotes household's total consumption expenditure, $\beta$ regression coefficient $\alpha$ is the intercept which account the food share when $Y_{i}=Z^{f}$, and $\epsilon$ is simply referring the error term. Then after the computation of the value of $\alpha$, the non-food share of expenditure is $(1-\alpha)$ and then the total absolute poverty line is:

$$
\mathrm{Z}^{\mathrm{T}}=\mathrm{Z}^{\mathrm{f}}(2-\alpha) \text {, where } \mathrm{Z}^{\mathrm{T}} \text { is total poverty line. }
$$

\subsubsection{Poverty indices}

Once the welfare measure as well as poverty line is determined, the remaining is to construct a single index to summarize the available information on the poor. There are a number of poverty indices developed by different scholars once [15] bring the issue into the picture and put ground for its further development.

[3] group of poverty measure indices become the most popular class of poverty indices used in the theoretical and empirical studies of poverty in nowadays as compared to other poverty measure indices developed by [17, 5]. FGT poverty measure is highly dominate and preferred to other poverty measures due to its ethical flexibility (captured by the parameter $\alpha$ ), decomposability across subgroups, sub- group consistency, ability to capture the most desirable properties of a poverty indices and understandability. Therefore, these groups of poverty measures are used in this study. The FGT poverty measure is specified as:

$$
\mathrm{P}_{\alpha}=\frac{1}{\mathrm{~N}} \sum_{\mathrm{h}=1}^{\mathrm{q}}\left[\frac{\mathrm{Z}-\mathrm{Ch}}{\mathrm{Z}}\right]^{\alpha}
$$

where, $\mathrm{Z}$ is the poverty line, $\mathrm{q}$ is the number of households below the poverty line, $\mathrm{N}$ refers to the number of households in the reference population/total sampled population, $\mathrm{C}_{\mathrm{h}}$ denotes Per adult equivalent consumption expenditure of household $h$ below the poverty line $\quad\left(C_{h} \leq \mathrm{Z}\right)$ in time period $t$. Moreover, ${ }^{1} \alpha$ is a nonnegative parameter indicating the degree of sensitivity of the poverty measure to inequality among the poor. It is known as poverty aversion parameter.

When $\alpha=0, \mathrm{P}_{\alpha}=\frac{\mathrm{q}}{\mathrm{N}}$. It refers as a head count ratio index and measures the proportionate of the poor households in the total population. This figure simply shows the incidence of poverty in the whole population. The head count index is insensitive to the distribution of income among the poor and does not reflect the situation when the poor become poorer or poorer become less poor. It has provided a poor guide for the resource allocation since it unable to distinguish the barely poor households among the poor if the goal of policy maker is to reduce head count index. However, it used to assess the overall progresses in poverty reduction.

When, $\alpha=1, \mathrm{P}_{\alpha}=\frac{1}{\mathrm{NZ}} \sum_{\mathrm{i}=1}^{\mathrm{q}}(\mathrm{Z}-\mathrm{Ch})$, the figure simply gives the poverty gap and it measures by how much income or consumption expenditure on average the poor far from the poverty line. Moreover, it could be understood as what amount of resources required on average to fill the gap that exists between the consumption of the poor and the poverty line. Like the head count index, poverty gap index fails the transfer sensitivity axiom.

When, $\alpha=2, \mathrm{P}_{\alpha}=\frac{1}{\mathrm{NZ}}\left(\sum_{\mathrm{i}=1}^{\mathrm{q}}\left(\mathrm{Z}-\mathrm{C}_{\mathrm{h}}\right)\right)^{2}$, This is a known as the severity of poverty. This index takes into account inequality among the poor in addition to the existing distance detaching the poor from the poverty line, and it gives a higher weight on those households further away from the poverty line.

\subsection{Modeling Non-Farm Activity Participation}

A farm household's decision either to participate in non-farm work or not is assumed to be the outcome of a vector of factors related to the farmers' resources and constraints. As noted by [5], a positive number of non-farm hours will be observed for an individual if the potential market wage is greater than the reservation wage. However, these differential wages are not observable. What is observed is the decision to participate, or not to participate in nonfarm work. This study postulates that a farm household will only engage in non-farm work when it gains extra income to complement its farm income (reservation wage). The study begins by observing participating and nonparticipating households, as to whether they differ significantly in terms of household characteristics, farm characteristics and assets. Thus, Logistic regression model is employed to estimate the determinants of participation in non-farm activities and to generate estimates for propensity scores.

Based on theoretical and empirical considerations, we specify the following model for non-farm employment participation:

$$
\begin{gathered}
\text { Nfarm }=\beta_{0}+\beta_{1} \text { sexhead }+\beta_{1} \text { agehead }+\beta_{3} \text { agesqu }+\beta_{4} \text { married }+\beta_{5} \text { educ } 8 \text { head } \\
+\beta_{6} \text { hhsize }+\beta_{7} \text { child }+\beta_{8} \text { depratio }+\beta_{9} \text { skill }+\beta_{10} \text { accredit }+\beta_{11} \text { hhland }
\end{gathered}
$$

\footnotetext{
${ }^{1}$ The value of a determines the relative weight given to the very poor in the index.

As $\alpha$ increases, greater weights are placed on the poorest.
} 


$$
+\beta_{12} \text { irrigacc }+\beta_{13} \text { dismkt }+\beta_{14} \text { disroad }+\varepsilon
$$

The dependent variable is individual participation in remunerative non-farm activities ( $N$ farm $)$ and takes the value 1 if the household participates in non-farm activities, zero otherwise. Selection of explanatory variables relies on previous empirical work on the determinants of participation in remunerative non-farm activities. The explanatory variables include: individual and household characteristics, household assets, location characteristics and access to infrastructure comprises. The outcome variable for this study is consumption expenditure per adult equivalent per month, as a proxy, to measure households' poverty level. The definition and measurement of the variables are presented in Table 1.

TABLE 1: CODES, DEFINITION AND MEASUREMENT OF VARIABLES

\begin{tabular}{|c|c|}
\hline Variable Codes & Definition and Measurement \\
\hline \multicolumn{2}{|c|}{ Treatment Variable } \\
\hline Nfarm & 1 if the $\mathrm{HH}$ head participate in non-farm activities, 0 otherwise \\
\hline \multicolumn{2}{|l|}{ Outcome Variable } \\
\hline Poverty level & Consumption expenditure per adult equivalent per month \\
\hline \multicolumn{2}{|c|}{ Explanatory Variables } \\
\hline sexhead & 1 if the household head is male, 0 otherwise \\
\hline agehead & Continuous variable refers to the age of the household head \\
\hline agesqu & Continuous variable, square of the household head age \\
\hline married & 1 if the household head is married, 0 otherwise \\
\hline educ8head & 1 if the household head is at least primary school complete, 0 otherwise \\
\hline hhsize & Continuous variable, Number of family members in a household \\
\hline depratio & $\begin{array}{l}\text { Continuous variable of the ration of (children under age of } 15 \text { and old age of above } 65 \text { to } \\
\text { active labor force) }\end{array}$ \\
\hline skill & 1 if the household head possess special/transferable skill, 0 otherwise \\
\hline acccredit & 1 if household head with access to credit, 0 otherwise \\
\hline hhland & Continuous, size of farms owned in hectare \\
\hline irrigacc & 1 if the household has access to irrigation, 0 otherwise \\
\hline dismkt & Continuous, distance from house to nearest market measured by kilometer \\
\hline disroad & Continuous, distance from house to main road measured in kilometer \\
\hline
\end{tabular}

\subsection{Propensity Score Matching and Treatment effects}

As with any impact evaluation, the main problem with identifying the impact of participation in non-farm employment is that the outcome indicator for participant households with and without participation in non-farm work is not observed because we only have information on the households once they participate in the non-farm activities, there is need to identify a control group that allows us to infer what would have happened with nonfarm activities participant household if participation would not have been in place.

To examine this causal effect of non-farm employment participation on poverty, the propensity score matching (PSM) method is employed. The propensity score $p(X)$ is defined as the conditional probability of receiving a treatment given pre-treatment characteristics [16]. Thus,

$$
\mathrm{p}(\mathrm{X}) \equiv \operatorname{Pr}[\mathrm{T}=1 \mid \mathrm{X}]=\mathrm{E}[\mathrm{T} \mid \mathrm{X}] ; \mathrm{p}(\mathrm{X})=\mathrm{F}\{\mathrm{h}(\mathrm{X})\}
$$

where $T=(0,1)$ is the indicator of non-farm work participation and $X$ denotes a vector of pre-participation characteristics, $F\{$.$\} can be a normal or logistic cumulative distribution. The propensity score can be predicted$ with either the logit or probit model [2].

The predicted propensity scores can then be used to estimate treatment effects. The most common treatment effects in the evaluation literature include the Average Treatment Effect (ATE) which captures the treatment effect for the whole sample, Average Treatment Effect on the Treated (ATT) or the participation effect, and the Average Treatment Effect on the Untreated (ATU). However, the parameter of interest in the estimation of the propensity score is the Average Treatment Effect on the Treated (ATT) which can be estimated as $\mathrm{ATT} \equiv \mathrm{E}\left\{\mathrm{Y}_{\mathrm{i}}^{1}-\mathrm{Y}_{\mathrm{i}}^{0} / \mathrm{T}_{\mathrm{i}}=1\right\}=\mathrm{E}\left\{\mathrm{E}\left\{\mathrm{Y}_{\mathrm{i}}^{1} / \mathrm{T}_{\mathrm{i}}=1, \mathrm{p}\left(\mathrm{X}_{\mathrm{i}}\right)\right\}-\mathrm{E}\left\{\mathrm{Y}_{\mathrm{i}}^{0} / \mathrm{T}_{\mathrm{i}}=0, \mathrm{p}\left(\mathrm{X}_{\mathrm{i}}\right)\right\} / \mathrm{T}_{\mathrm{i}}=1\right\}$

where, $i$ denotes the $i^{\text {th }}$ household, $p\left(X_{i}\right)$ is the p-score, $E\left(Y_{i}^{1} / T_{i}=1\right)$ is the per adult equivalent consumption expenditure (as a proxy, to measure households' poverty level) for household with access to nonfarm activities and $E\left(Y_{i}^{0} / T_{i}=0\right)$ is the per adult equivalent consumption expenditure for household with no access to non-farm activities.

For robust estimation of the propensity score, a balancing property which is a function of the relevant observed covariates must be satisfied. This property implies that conditional on the propensity score, each individual should have the same probability of participating in non-farm work as in a randomized experiment. As noted by [6], the distribution of $\mathrm{X}_{\mathrm{i}}$ is expected to be balanced in the two samples if this balancing property is satisfied. Another relevant assumption for robust estimation of the $p$-score is to satisfy the common support 
condition [4]. This requires that individuals with the same covariates X should have positive probabilities of being both participants and non-participants in non-farm work, implying that all individuals in the common support region can actually participate in all states $(0<P(\mathrm{~T}=1 \mid \mathrm{X})<1)$. [17] point out that if there are regions where the support of $\mathrm{X}$ does not overlap for the different groups, matching is only justified when performed over the common support region and the estimated treatment effect must be redefined as the treatment impact for participants whose probabilities lie within the overlapping support region. Given the propensity score, the Conditional Independence Assumption (CIA) must also be satisfied. This states that once the set of observable characteristics, X, are controlled for, the treatment variable (cash-oriented non-farm activities participation), and the outcome variable (consumption expenditure per adult equivalent per month) should be uncorrelated.

A number of matching algorithms have been suggested in the literature to match participants and nonparticipants of similar propensity scores. The most widely employed algorithms include the nearest neighbor matching, caliper matching, and the kernel matching methods. Once the common support region identified, the next step is searching the appropriate matching algorithms. The appropriate matching algorithm should be selected by observing three criteria in the result that are: the balancing test, the reduction in standard, pseudo- $\mathrm{R}^{2}$ and matched sample size [14]. Thus, a matching algorithm which balances the most explanatory variables, results in a low pseudo- $\mathrm{R}^{2}$ value, reduces more standard bias and also results in large matched sample size should be selected.

\subsection{Data set}

Primary and secondary data were the main source of data in this study. In order to obtain the primary data, a cross sectional field survey was adopted using structured questionnaire. Accordingly, household interview was conducted to a total of 300 rural farm households: 150 households were identified as participant and 150 as nonparticipant in remunerative non-farm activities. The interviewed households from the two groups (participants and non-participants) from each kebele were similar in their observable characteristics to minimize the problem of heterogeneity except for participation in non-farm activities. Secondary data was obtained through extensive literature review from various local and international reports and publications. The documents which were reviewed involve journals, books, official reports and previous researches.

\section{Results and Discussions}

\subsection{Measuring poverty in Ambo district}

4.1.1. Poverty line in the study area

As stated in the methodology part, the absolute poverty line used in this study was derived using the cost of basic needs (CBN) approach, which involves 25 food items consumed by the poorest $50 \%$ of sample household accessed and used to construct the absolute poverty line. In the derivation of the poverty line and consumption expenditure per adult equivalent household size, the amount of consumption goods, which is measured by different units were converted into a single unit of measurement (kg and litter) using the respective equivalent scales obtained from field works. Finally, the study used the median price in order to alleviate price variations from market to market, and people's preference. After identifying the food items consumed by reference household and make a necessary price adjustment, the amount of food items obtained from reference household determined based on the predetermined level of minimum calorie requirement. Then, the selected food items scaling up and down until the daily minimum calorie requirement per adult equivalent household size of $2200 \mathrm{Kcal}$ achieved, and the amount of food items, which supplied the minimum calorie requirement valued at market price.

By having the median price, absolute food poverty line of 283.87 Birr per adult equivalent per month was derived, and the non-food poverty line also constructed by following the approach described in [11] and finally 380.38 Birr per adult equivalent per month adopted as an absolute poverty line in this study. This absolute poverty line reflects the current condition in the study area like price, consumption preference and tests of the households, norms, consumption habits. More or less, it also reflects the type of food items grown in the study area.

TABle 2: ABSOLUTE POVERTY LINE OF THE STUDY AREA PER MONTH PER ADULT EQUIVALENT (ETB) AT THE CURRENT MARKET PRICE

\begin{tabular}{lc}
\hline Poverty line & Value at market price \\
\hline Food poverty line & 283.87 \\
Non-food poverty line & 96.51 \\
Total poverty line & 380.38 \\
\hline
\end{tabular}

Source: Compute from own survey, 2017.

\subsubsection{Poverty Profile}

Given the poverty line estimated in the study area, households grouped into the poor (those who have not sufficient spending to meet the minimum calorie requirement per month) and the non-poor that the households having enough spending to acquire the minimum monthly calorie requirement. Table 3 reveals that $26.33 \%$ of households in the study area are poor and the remaining $73.67 \%$ are considered non-poor at an absolute total poverty line. These figures emanated from the estimation of absolute poverty line based on adult equivalent consumption of 
basic needs, and then grouping people who spends below Birr 380.38 per adult equivalent per month considered as poor, and those who spend above Birr 380.38 are non-poor. The overall depth of poverty (poverty gap) and severity of poverty (poverty gap square) are about $18.76 \%$ and $4.50 \%$, respectively.

Moreover, Table 3 presents the poverty profile of the participant and non-participant households using FGT poverty measure. That is, $27.33 \%$ of non-participant households are poor, compared to $25.33 \%$ of participant households. The poverty gap was also higher for non-participant, $19.67 \%$, than participants, $17.78 \%$. Finally, the severity of poverty result also showed difference between participants, 4.04\%, and non-participants, $4.93 \%$. Table 3: Poverty estimates for participant and non-participant households

\begin{tabular}{lccc}
\multicolumn{1}{c}{ Poverty indexes } & Overall & Participant & Non-participant \\
\hline Head count $\left(\mathrm{P}_{0}\right)$ & 26.33 & 25.33 & 27.33 \\
Poverty gab $\left(\mathrm{P}_{1)}\right.$ & 18.76 & 17.78 & 19.67 \\
Poverty gap square $\left(\mathrm{P}_{2}\right)$ & 4.50 & 4.04 & 4.93 \\
\hline
\end{tabular}

Source: Compute from own survey, 2017.

4.2. Descriptive Statistics and Mean Tests

Figure 4: Descriptive statistics for participation in non-farm economic activities

\begin{tabular}{|c|c|c|c|c|c|}
\hline \multirow[t]{2}{*}{ Variable Name } & \multicolumn{2}{|c|}{ Participants } & \multicolumn{2}{|c|}{ Non-participants } & \multirow[b]{2}{*}{ t-test } \\
\hline & Mean & $\mathrm{SD}$ & Mean & $\mathrm{SD}$ & \\
\hline \multicolumn{6}{|l|}{ Treatment Variable } \\
\hline \multicolumn{6}{|l|}{$\begin{array}{l}\text { Participate ( } 1 \text { if the } \mathrm{HH} \text { head participate in } \\
\text { non-farm activities, } 0 \text { otherwise) } \\
\text { Outcome Variable }\end{array}$} \\
\hline $\begin{array}{l}\text { Consumption expenditure per adult } \\
\text { equivalent per month in birr }\end{array}$ & 509.33 & 194.00 & 449.61 & 121.57 & $3.19 * *$ \\
\hline \multicolumn{6}{|l|}{ Independent Variables } \\
\hline Sex of HH Head & 0.81 & 0.39 & 0.94 & 0.24 & $-3.38 * * *$ \\
\hline Age of HH Head & 40.24 & 9.96 & 44.58 & 12.63 & $-3.30 * * *$ \\
\hline Square of HH Heads' Age & 1717.88 & 857.48 & 2145.91 & 1212.37 & $-3.53 * * *$ \\
\hline Marital status of HH Head & 0.81 & 0.39 & 0.55 & 0.49 & $4.87 * * *$ \\
\hline Education of HH Head & 0.73 & 0.44 & 0.64 & 0.48 & 1.74 \\
\hline Household size & 4.70 & 1.63 & 4.82 & 1.75 & -0.62 \\
\hline Dependency ratio & 0.65 & 0.73 & 0.81 & 0.85 & $-1.75^{*}$ \\
\hline Transferable skill & 0.27 & 0.44 & 0.04 & 0.20 & $5.72 * * *$ \\
\hline Access to credit & 0.41 & 0.49 & 0.03 & 0.18 & $8.71 * * *$ \\
\hline Farm size & 1.51 & 1.13 & 1.92 & 1.58 & -2.59 \\
\hline Access to irrigation & 0.04 & 0.20 & 0.14 & 0.35 & -3.06 \\
\hline Distance from house to nearest market & 7.54 & 4.33 & 12.22 & 4.25 & $-9.44 * * *$ \\
\hline Distance from house to main road & 2.62 & 2.43 & 3.24 & 2.74 & -1.93 \\
\hline
\end{tabular}

$*, * * * * *$ indicate significant at $10 \%, 5 \%$ and $1 \%$ respectively. $\mathrm{SD}=$ standard deviation

Source: Compute from own survey, 2017.

Table 4 compares the characteristics of the participants and those that did not participate in the remunerative non-farm activities in the study areas. On average, the consumption expenditure per adult equivalent per month for the participant households, 509.33 birr, was significantly higher than the non-participant, 449.61 birr. Other variables such as gender, age, age square, marital status, dependency ratio, transferable skill, access to credit and distance from the nearest market had means which differed significantly between participant households and nonparticipant households. In general, most of the participant households are women, married, younger, have lower dependency ratio, possess transferable skill, and have access to credit compared to non-participant households. Participant households live in villages that are closer to market compared to non-participant households.

\subsection{The Econometric Model Results}

\subsubsection{Determinants of participation in non-farm activities}

To identify the factors that affect participation decision of households on non-farm activities, the Logit model was used to generate propensity scores from the matching algorithm. The result obtained was presented in Table 5 . The likelihood ratio chi-square value, 191.73, was found statistically significant at $1 \%$ significance level. This implies that, the model was statistically significant and the regression coefficients give the change in the Logit index or zscore for a unit change in the predictors. Moreover; the relative small value of Pseudo $\mathrm{R}^{2}(0.4610)$ indicates that there was no systematic difference in the distribution of covariates between participant and non-participant households in non-farm activities in the study area. 
Sex of household head (sexhead): Sex of household head has a significant and negative effect on the probability of non-farm activities participation, and it is statistically at $1 \%$ significance level implying that female headed households are more likely participate in non-farm activities than the male, and this may be connected to the difficulties associated with farming or physical strength required in farming activities. Thus, females were found to be more likely to participate in rural non-farm activities in the study area.

Marital status of household head (married): Coefficient of marital status of household head was positive and significant at $1 \%$ implying that married headed households are more likely participate in non-farm activities. This is due to the fact that married headed households have relatively more labour power and might be motivated to allocate labour into non-farm activity.

Dependency ratio (depratio): Dependency ratio has a negative and significant coefficient (at 10\%), this imply that households with a large number of dependents relative to the number of adult households play a negative role in cash oriented non-farm activities. Thus, the existence of dependent persons impedes other household members from leaving the household and working outside. This result is consistent with the findings of [8].

Special skill (skill): Possessing special skill has a significant and positive influence on the probability of non-farm activities participation, and it is statistically at 1\% significance level implying that skilled households are more likely to engage themselves in more paying non-farm activities. More specifically possessing skills such as masonry, handcrafts and merchants increase the probability of involvement in non-farm activities to the villages that are close the nearby towns while skills such as tannery, pot making, and goldsmith are associated to the villages that are far from towns. The skilled farm households have a positive interest in the involvement of non-farm activities in the study area. This may be because non-farm activities require some skills and training. Hence, households with some skill tended to engage in non-farm activities.

Access to credit (accredit): Access to credit is found to be one of the major determinants of participation in nonfarm economic activities. The coefficient of access to credit is positive and statistically significant at $1 \%$ significance level. Households with access to credit are more likely to participate in non-farm activities than those without access. Access to the credit market gives opportunities to farm households to get the necessary capital to start up or to be participated in non-farm employments. This positive relationship between non-farm activities participation and access to credit is similar to the finding of [13].

Distance from house to nearest market (dismkt): The coefficient of distance from the nearest market is negatively and statistically significant at $1 \%$ significance level, this shows that the nearer the distance to market the stronger the incentive to participate in non-farm activities. This is due the fact that the opportunities for labor market and less commuting cost. This is also similar to the study of [7].

Figure 5: Logistic estimates for calculating propensity scores.

\begin{tabular}{lcccc}
\hline Variable & Coefficient & Std. Error & Z-Value & $\mathrm{P}>/ \mathrm{Z} /$ \\
\hline Sex of HH Head & $-2.2998^{* * *}$ & 0.6919 & -3.32 & 0.001 \\
Age of HH Head & 0.0663 & 0.1218 & 0.54 & 0.586 \\
Square of HH Heads' Age & -0.0012 & 0.0013 & -0.93 & 0.352 \\
Marital status of HH Head & $2.2876^{* * *}$ & 0.5127 & 4.46 & 0.000 \\
Education of HH Head & 0.1983 & 0.4004 & 0.50 & 0.620 \\
Household size & 0.1978 & 0.1371 & 1.44 & 0.149 \\
Dependency ratio & $-0.4876^{*}$ & 0.2522 & -1.93 & 0.053 \\
Transferable skill & $2.8362^{* * *}$ & 0.6392 & 4.44 & 0.000 \\
Access to credit & $2.0973 * * *$ & 0.5622 & 3.73 & 0.000 \\
Farm size & -0.1569 & 0.1483 & -1.06 & 0.290 \\
Access to irrigation & -0.4104 & 0.6197 & -0.66 & 0.508 \\
Distance from house to nearest market & $-0.1795^{* * *}$ & 0.0386 & -4.65 & 0.000 \\
Distance from house to main road & -0.1167 & 0.0709 & -1.65 & 0.100 \\
Constant & 0.9084 & 2.5531 & 0.36 & 0.722 \\
\hline \hline Number of obs $=300$ & LR chi2(13) $=191.73$ & Prob $>$ chi2 $=0.0000$ \\
Log likelihood = -112.07 & Pseudo R2 $=0.4610$ & & \\
\hline$* * *, * *$ indicate significant at 5\% and 1 \% probability level, respectively & & \\
Source: Compute from own survey, 2017 & & &
\end{tabular}

\subsubsection{Propensity Score Matching (PSM)}

In analyzing the impact of non-farm activities on consumption expenditure per adult equivalent per month, as a proxy, to measure households' poverty level propensity score matching was used. The propensity score is computed based on the logistic model and they serve as a tool to balance the observed distribution of covariates across the treated and the untreated group. It was done using the "pscore" command in STATA to predict a propensity score between the two groups.

The estimated propensity score in the region of common support ranges from 0.0695228 to 0.99768 with a 
mean of 0.5994582 . Thus, the common support and overlap region for both control and treatment groups lies between 0.06952281 and 0.99768001 . Having common support and overlap region tells us the two comparison groups can make matching. Accordingly, 53 households from the control group were dropped from analysis of average treatment effects.

\subsubsection{The impact of the non-farm activities on household consumption expenditure}

The results of the treatment effect (ATT) for participation in remunerative non-farm activities was computed by the kernel matching algorithm (band width 0.06) which was found appropriate matching algorithm for the data presented for this study. It can be observed that this matching algorithm balances the most explanatory variables, results in a low pseudo- $\mathrm{R}^{2}$ value, reduces more standard bias and also results in large matched sample size.

As can be seen from table 7, the result on ATT indicates that non-farm employment has a positive relationship with household consumption expenditure. This implies, increased participation in non-farm activities increases the household consumption expenditure. The causal effects of 72.31 at $5 \%$ significant level indicate that household's participation in remunerative non-farm activities yield an increase in the household monthly consumption expenditure by birr 72.31. Thus, this finding indicates that households that have a higher probability of participation in remunerative non-farm activities are less vulnerable to poverty compared to households that do not participate in remunerative non-farm activities. Table 6: The impact of the non-farm activities on household consumption expenditure

\begin{tabular}{cccrrrrr}
\hline Outcome variable & Matching Method & $\begin{array}{l}\text { Number } \\
\text { Treated }\end{array}$ & $\begin{array}{l}\text { Number } \\
\text { control }\end{array}$ & of & ATT & S.E. & t-statistic \\
\hline Consumption & Kernel Matching & 150 & 97 & 72.31 & 34.22 & $2.11^{* *}$ \\
\hline
\end{tabular}

** denotes significant at 5\% probability level. S.E. = Standard Error

Source: Compute from own survey, 2017.

\section{Conclusion and Recommendation}

\subsection{Conclusions}

Among the 300 sample households in the study area $26.33 \%$ of the households were found to be poor implies that they could not get sufficient spending to meet the minimum calorie requirement per month. The result suggests that in spite of Ethiopia achieves remarkable success in halving consumption poverty there exists a relatively high level of problem of poverty in the study area as reflected by poverty incidence indices. Besides, the incidence of poverty was significantly lower among participants with $24.67 \%$ than non-participants of non-farm activities of $27.33 \%$.

The result of logit regression indicated that factors such as sex of household head, marital status of household head, dependency ratio, specific skills, access to credit, and distance from the nearest market as significant determinants of participation in remunerative non-farm activities. The propensity score matching results showed that participation in remunerative non-farm activities has a significant effect on the households' consumption expenditure level. The average treatment effect of treated indicated that, the average monthly per capita consumption expenditure of participant is birr 72.31 more than non-participants households. Thus, participation in remunerative non-farm activities improved the livelihood of households in the study district.

The results imply that there is a need to promote non-farm economic activities opportunities in the study district, given its effect on consumption expenditure. Any policies targeted at alleviating poverty should go beyond just food production measures; they should include both food production measures and measures that help generate additional incomes for rural farm households through the development of alternative livelihood opportunities. Not only is diversification into non-farm work a dependable supplementary source of income for rural households, it also helps in smoothing income and consumption. Thus, while this study is not advocating for non-farm economic activities as a substitute to farming, non-farm economic activities could be a reliable complement to farming activities. The promotion of non-farm activities in addition to farm activities seems indispensable to alleviate rural poverty.

\subsection{Recommendation}

In countries like Ethiopia, where subsistence agriculture and the small holding farm are dominates in the overall National Economy. Even though agriculture is the backbone of Ethiopia's economy, it will no longer provide sufficient employment for the growing rural labour force through time. Therefore, a great part of the surplus agricultural labor must leave the agricultural sector, and non-farm activities will thus continue to play a critically important role in rural development and poverty reduction.

The study suggest that non-farm economic activities provide rural households in Ambo district with an opportunity to manage household food security, reducing poverty and improve living conditions. Income from the non-farm sector is likely to enable rural households to increase their purchasing power, enabling increased expenditure on food and consequently increasing access to food. Thus, ensuring these at the household-level should also involve strategies that create opportunities and expansion of non-farm micro-enterprises in the rural 
economy.

Policy efforts should be geared towards encouraging easy entry into the non-farm sector by both males and females through improvement of human capital endowments and skill building. Expanding the effective extension services to increase awareness among rural farm households in using family planning to limit the number of children in a household to get a healthy and productive family member that are both physically and financially strong to make decision. Provision of skills training at local level specifically focused on building technical and managerial skills necessary to rural people, to enable them realize their potential and effectively undertake new types of activities. Improving access to credit would promote participation and performance of rural non-farm activities. To achieve this goal effectively, more emphasis should be placed on promotion of savings and credit schemes and also through assistance from non-governmental organization and donors involved in provision of microfinance schemes. Moreover, improving rural access market is of paramount importance in the performance of rural non-farm activities in turn as poverty alleviation strategies in rural setting.

\section{References}

[1] De Janvry, A. and Sadoulet, E. (2001). Income Strategies Among Rural Households in Mexico: The Role of Off-Farm Activities. World Development, 29(3):47-480.

[2] Faltermeier, L. and Abdulai, A. (2009). The impact of water conservation and intensification technologies: empirical evidence for rice farmers in Ghana. Agricultural Economics 40(3):365-279.

[3] Foster, J., Greer, J., Thorbecke, E. (1984). A Class of Decomposable Poverty Measures. Econometric, Vol. 52, No. 3, Pp. 761-766.

[4] Heckman, J., LaLonde, R. and Smith, J. (1999). The economics and econometrics of active labor market programs. In Handbook of Labor Economics, Vol. III, Ed. By O. Ashenfelter, and D. Card, pp. 1865-2097. Elsevier, Amsterdam.

[5] Huffman, W.E. (1991). Multiple jobholding among farm families. In: Agricultural Households Survey and Critique. Edited by J.L. Findeis, M.C. Hallberg and D.L. Lass. Chapter 5, Iowa State University Press, 1991, Ames IA, USA.

[6] Hujer, R., Caliendo, M. and Thomsen, S.L., (2004). New evidence on the job creation schemes in Germany- a matching approach with threefold heterogeneity. Research in Economics 58:257-302.

[7] Kassim, M. (2011). Determinants of Participation in Non-farm Economic Activities in Rural Zanzibar; African Centre for Food Security, School of Agricultural Science and Agribusiness, Faculty of Science and Agriculture, University of KwaZulu-Natal, Pietermaritzburg

[8] Lanjouw, J., Lanjouw, P. (2001). The Rural Non-farm Sector: Issues and Evidence from Developing Countries. Agricultural Economics 26(1): 1-23.

[9] Mduma, J.,Wobst, P. (2005). Determinants of Rural Labor Market Participation in Tanzania Volume 8, Issue 2

[10] Owusu, V. and Abdulai, A. (2009). Non-farm Employment and Poverty Reduction in Rural Ghana: A Propensity-Score Matching Analysis. Contributed Paper Prepared for Presentation at the International Association of Economists Conference, Beijing, 16-22 August 2009, 1-16.

[11] Ravallion, M., Bidani B. (1994). How Robust Is To A Poverty Profile? The World Bank Economics Review, 8(1), Pp.75-102

[12] Reardon, T. (1997). Using Evidence of Household Income Diversification to Inform the Study of Rural Nonagricultural Labour Market in Africa. World Development, 25(5): 735-748.

[13] Reardon, T., Berdague, J., and Escobar, G. (2001). Rural Nonfarm employment \& Incomes in Latin America: Overview \& Policy Implications. World development 29, 395-409.

[14] Rosenbaum, P.R. and Rubin, D. (1983). Constructing a Control Group Using Multivariate Matched Sampling Methods that Incorporate the Propensity Score. The American Statistician, 39, 33-38.

[15] Sen., A.K. (1976). Issues in the measurement of poverty. Scandinavian journal of economics, 8 (1): 285-307.

[16] Siti Hadijah, C.M., Nor' Aznin, A.B., and Ahmad Zafarullah, A.J. (2011). The Impact of Non-Farm Income on the Incidence of Poverty among Farmers in Kedah, Malaysia. International Journal of Trade, Economics and Finance, Vol. 2, No. 4

[17] Smith, J. and Todd, P. (2005). Does matching overcome LaLonde's critique of non-experimental estimators? Journal of Econometrics 1251-1252.

[18] Theodros Girma. (2012). Farm assets and nonfarm activities characteristic and determinants of nonfarm activities in small holder farmers: The case of North east Ethiopia, Tehuledere District.

[19] Woldehanna, T. (2000). Economic analysis and policy implications of farm and off-farm employment: a case study in the Tigray Region of Northern Ethiopia.

[20] World Bank. (2005). Introduction to Poverty Analysis', Washington DC, the World Bank

[21] World Health Organization [WHO], (1985). Physical status: The use and interpretation of anthropometry. WHO technical report series 854, Geneva, Switzerland. 